\title{
Government, Here to Help!
}

\author{
Manisha Mirchandani
}

When Yao Li sought to set up a free-of-charge vocational education school for the children of migrant workers in Beijing, she had the ideal background for the challenge. A prominent Chinese businesswoman, she tapped into her extensive network of contacts to garner support for Bainian Vocational School (BNVS). It now comprises nine branches in major Chinese cities plus an international branch in the capital of Angola, all under the direction of an illustrious board assembled by Yao Li, including former housing adviser to the Hong Kong government Simon Li, and well-known media personality and former CCTV journalist Wang Jie.

But it was a fortuitous meeting with the China Youth Development Foundation (CYDF) that cemented the launch of BNVS and its eventual success. CYDF, one of the country's oldest and largest national public foundations, has a particularly important network. With this partnership as a foundation, BNVS was able to succeed in spectacular fashion. Around 2500 underprivileged young people from across China graduated from its programs from 2005 to 2015 , trained as skilled workers. ${ }^{1}$

CYDF's clout means that it plays an important role in setting the national youth development agenda, one amplifying the reach of its graduates and personnel. Founded by the All China Youth Federation, it was the driving force behind Project Hope, a national initiative that had sup-

M. Mirchandani

CAPS, Hong Kong SAR, China

(C) The Author(s) 2018

R.A. Shapiro et al., Pragmatic Philanthropy, https://doi.org/10.1007/978-981-10-7119-5_6 
ported 5 million students in rural areas to continue their education by 2013. As a partner, CYDF could offer Yao Li not just experience but prominence and broad approval. Tu Meng, then vice chairperson and secretary general of CYDF, knew Yao Li faced a challenging maze of laws and regulations to establish a nonprofit school if she pursued them alone. "What you are missing, we have it all," he told her.

\section{Reimagining the Social Contract}

$\mathrm{Tu}$ and Yao Li soon reached an agreement whereby CYDF would subsidize BNVS from its own Vocational Education Fund. And through this affiliation with CYDF, BNVS could now undertake public fundraising, which was to prove a crucial factor in its development and future growth.

Their partnership reflected currents in the country as a whole. Their initial discussions took place amid a long-term shift in how the Chinese government viewed the social sector's developmental role. In the past, the majority of social services, and practically all education services, were provided by the state. That began to change in the 1990s, as China began a process of economic reform that included considering different approaches for public service delivery.

In China, the practice of procuring nonprofit contractors to deliver education and health care services on behalf of the state is not as well established as in some other countries. As Beijing began collaborating with both the private sector and social organizations to explore new models of service delivery, CYDF was at the forefront of this movement in education. It would be a critical partner in piloting the BNVS model for vocational schooling.

This offered a pathway for migrant children unable to access the formal education system due to strict residency requirements while also responding to a growing demand in China's labor market for more serviceoriented, technically skilled workers. Perhaps drawing inspiration from the success of the BNVS, the government has since announced plans to increase the number of vocational education schools countrywide, with a target of providing universal free-of-charge training.

This shift in public-sector thinking is not limited to China. Governments across Asia have become increasingly open to new ways of financing and delivering on public expectations as the social contract forged with their citizens comes under increasing strain. In the wave of postwar independence, new governments across the region had attempted to bring together fragmented and diverse societies through a unifying vision, as exemplified through Jawaharlal Nehru's interconnected India, and 
Sukarno's harmonizing Pancasila principles in Indonesia. In other countries, the contract that was brokered was more transactional, with the promise of public services and prosperity in exchange for social stability. From Lee Kuan Yew's Singapore to Mahathir's Malaysia to Deng Xiao Peng's modern China, this deal helped to foster the stability required for East Asia's economic ascent.

In the more developed economies of the region, traditional pathways to social mobility are becoming closed off. A new generation is no longer seeing sufficient returns on acquiescence and are demanding a greater voice in decision-making. The student-led Umbrella Movement of Hong Kong in 2014 demanded broader representation in selection of its leaders, and opposition parties in Singapore rose on the support of young people via social media channels. In the developing countries of Asia, many with large, young populations, governments are under pressure to raise living standards and provide jobs to quell discontent-for example, Indonesia's youth unemployment rates remain worryingly high at 21 percent, according to World Bank data. This is all taking place in the wake of the 2008 global financial crisis and subsequent economic shocks, when fiscal pressures on the public purse have never been greater.

\section{For Service Delivery}

Amid this changing social dynamic in Asia, domestic social delivery organizations (SDOs) are emerging to play a more prolific role in public service delivery. Multilateral development agencies encourage collaborative models of partnership between the government and non-traditional actors in the delivery of health care, education, poverty alleviation, and environmental services. It has not always been so: SDOs in Asia have not historically been so broadly interested in collaboration models. But now, partnership with government has become all but essential to achieving their aims. Across the 30 nonprofits and social enterprises studied, there are few exceptions to this rule. A closer look at the high performers in their countries shows us various ways to partner with government across the region, collaboration taking place at different phases in the evolution of the SDO. Indeed, the arrangements being struck are as diverse as the countries of Asia themselves.

The most straightforward means by which to work with government is to be contracted by government to carry out social delivery services. Of the 15 economies in our Doing Good Index study, all allow for the procurement of services of SDOs to deliver social goods, although six go further and add incentives for SDOs to compete for government contracts. 
In fact, in Hong Kong, of the 450 SDOs listed with the Hong Kong Council of Social Services Wise Giving platform, 49 percent of their aggregated budgets come from government contracts, the highest among the countries we studied. As noted in Chapter 2, there are historical reasons for this. In economies where colonialism played a formative role, the government simply did not have the desire or bandwidth to carry out social delivery functions. They contracted out these tasks to local groups. In the case of Hong Kong, this practice continues today through government procurement schemes.

Although the enthusiasm for working with government partners varies depending on domestic dynamics, direct engagement with government is broadly necessary at some stage for SDOs to thrive. As our case studies indicate, there comes a time when the founder or manager will likely reflect on how it will forge its relationship with relevant government entities. More often than not, it is not a case of considering why they should work with government but usually a matter of when and how.

\section{As JV PARTNERS}

To achieve their objectives, some SDOs were established with an understanding that they would need to partner with government to even make it onto the playing field. Recognizing the value of this form of endorsement, such "joint ventures" (JVs) are sought willingly by SDO founders.

The joint venture struck between Yao Li and Tu Meng was critical to the BNVS concept even getting off the ground. Right at the start, domestic fundraising posed a major barrier to BNVS' efforts, which required government authorization for nonprofit schools. Through its affiliation with CYDF, BNVS was able to fundraise within Mainland China, eventually coming to depend almost exclusively on domestic funding. By the 2013-2014 school year, 86 percent of its income came from domestic sources, rising to 93 percent the next year. In addition, BNVS benefited from free-of-charge usage of CYDF premises-classrooms for the Zhengzhou school were provided by the Henan Communist Youth League, a CYDF member. The CYDF connection has also been helpful in recruiting for BNVS, a virtual unknown in its early days, enabling it to attract the teaching capacity required for its schools to run.

Through CYDF, the government has remained a controlling stakeholder and interested observer of Yao Li's experimental model. Tu Meng, also a BNVS board member, acted as an important conduit between 
government and BNVS while providing a lens for BNVS into the government's plans for the vocational sector and youth development. But most critical to Yao Li's success has been the official seal of approval stamp BNVS received by its partnership with the government-affiliated CYDF, which Tu described as a "successful innovation."

In Malaysia, we found a much more explicit arrangement struck between the government and the Sports Racquet Association of Malaysia (SRAM). Established in the 1972 by young Malays and expatriates who played the game at exclusive clubs in Kuala Lumpur, SRAM's founding purpose was to popularize the game of squash in Malaysia. Its major benefactor today, the National Sports Council (NSC) of the Ministry of Youth and Sports, began supporting the association in the 1990s in the wake of Malaysia's winning bid for the 1998 Commonwealth Games. The government threw its support behind SRAM and other sports groups in a bid to help the nation's athletes win prestige for Malaysia, spending more than US\$468 million on the games. SRAM worked primarily at the state level, building facilities, recruiting young athletes, and developing a world-class training program.

In addition to financial support, the government also intervened to connect SRAM to sources of corporate funding. In 1995, the Ministry of Youth and Sports introduced a program known as Rakan Sukan (sports partner) to encourage Malaysian corporations to adopt a sport and provide the requisite financial assistance and management training to help elevate it to international standards. Industry responded to the call, and SRAM was matched with YTL Corporation Berhad, a Malaysian infrastructure conglomerate founded by business tycoon Francis Yeoh Tiong Lay. From 1996 to 2003, YTL contributed US\$1.3 million, until the baton was subsequently taken up by Nazir Razak, squash player and chief executive officer of CIMB Bank, who remained a primary corporate sponsor for SRAM till 2015.

Through the NSC, the government continues to be the biggest sponsor of SRAM's programs and its athletes, providing 56 percent of its total funds in 2014. As a direct investor, the government was in essence funding SRAM as an extension of the national sports program, an approach possible only given the perfect alignment of their objectives to elevate squash as a national sport. SRAM's founding vision to democratize squash and develop world-class players aligned perfectly with that of the Malaysian government seeking to raise the country's global sporting image. SRAM was perceived to be an effective vehicle with the expertise and networks to develop sporting talent at the grassroots level—where a Malaysian superstar 
was discovered. International sporting icon Nicol David, who has won the World Squash Open a record-breaking eight times, is a shining example of this joint venture's success.

\section{As Venture Funders}

Public grants and subsidies now give Asia's social sector access to funds long available for economic development. Historically, governments of the region have utilized subsidies to support the growth of strategic sectors, including the electronics industry in Japan, South Korea, and Taiwan. This concept is now trickling through the social sector, as governments redirect subsidies toward new growth areas, such as renewable energy and environmental services. The social enterprises in our study have benefited from this pivot by capitalizing upon new procurement opportunities that have arisen from Asian governments eager to develop their green economies.

Building a social enterprise around tree planting was very much a bluesky idea for Tree Planet co-founder Jeong Mincheol. But rather than join a nonprofit that specialized in reforestation, Jeong wanted to prove that it was possible to build a profitable business that could also have a real environmental impact. Noting the Korean government's Green Growth policy agenda and the support that was being made available to industry, Jeong and his co-founder Kim Hyungsoo went to the market with an idea for selling customized replanting projects to consumers.

With the demand for environmentally minded products and services being stimulated, Tree Planet was able to thrive as a profitable business, with revenues of close to US\$1 million in 2015. Alongside the K-pop fans who pay Tree Planet to plant and personalize forestry projects dedicated to their idols, the Seoul Metropolitan Government has been a consistent client of the organization in urban replanting initiatives.

Green growth is also blooming in China. Since the Chinese government prioritized the green economy within its 12th Five-Year Plan for 2011-2015, government agencies right down to the municipal level have received significant financial support to put toward environmental spending. This has paid off for social enterprise Landwasher, the developer of an environmental toilet that can save an estimated 2.2 tons of water and around 7300 kilowatt hours of electricity a year compared to a traditional portable model. Now with assets of US\$10 million, Landwasher has installed more than 10,000 of its toilets across the country, making it China's top waterless toilet-solution provider. 
Deciding that the concept of a social enterprise was still confusing to the domestic Chinese market, Wu prefers to call his company an "environmental enterprise," as the term is less likely to be associated with sensitive nonprofit activities in the Chinese non-governmental sector. It also directly links his proposition to funding earmarked for "green" solutions, helping him open doors to government agencies such as the tourism bureaus and local development departments that remain Landwasher's client base. Its core business is in installing mobile toilets in remote tourist areas and municipal areas off the grid from urban sanitation and sewer systems. Its big breakthrough came in 2008, when it was selected from more than 200 bidders to supply water-free toilets for the Olympic Games in Beijing. From there on, it has been the supplier of choice for other premium largescale events in China, such as the 60th Anniversary Celebration of the People's Republic of China, for which it provided 350 movable toilets.

Government subsidies have also benefited Landwasher in less direct ways. Local government agencies have played an important role in supporting Landwasher's development. Its classification as a high-tech enterprise means that it is eligible for tax and financing benefits and other forms of enterprise support from the Langfang, Hebei Province authorities. But primarily, Landwasher interacts with government agencies as a preferred vendor. Public-sector contracts remain the bread and butter of its business, to the extent that Wu categorizes his company as being in the "business-to-government" sector.

Getting buy-in from government actors was a similar factor in the success of the Center for Agriculture and Rural Development (CARD), a Filipino social enterprise. Established in 1986, CARD has developed a network of "Mutually Reinforcing Institutions" (MRI) to extend access to financial services to the rural poor. The CARD MRI network reaches far and deep into several provinces in the Philippines, a nation of 100 million, of whom an estimated 25 percent are considered poor. CARD has been extremely successful with more than one million loans and 8 million insurance customers.

Its engagement with government kicked in when the organization's founder, Jaime Aristotle Alip, sought to take CARD to the next level in 1995. CARD's loan portfolio had already grown from 200 borrowers in 1988 to 4240 through the implementation of a microfinance group lending model. But Alip wanted to do more; he had a vision of creating Philippines' first microfinance bank to be managed and partly owned by up to 1 million poor members. Upon being granted a license by the Philippines Central Bank, CARD Bank was established in September 1997. 
In growing its network of MRIs, CARD increasingly worked with relevant branches of the Philippines national government, including the Central Bank, the Insurance Commission, and the Securities and Exchange Commission (SEC), to facilitate conditions conducive to the proliferation of microfinance. With the SEC, it developed commercial notes, a shortterm debt instrument for corporations, for microfinance clients. CARD MRI's lobbying efforts led to changes in law that officially recognized microfinance as a legitimate form of banking in 2000. This has set the stage for the sector's growth since then, and the implementation of microfinance-based models for a wide range of services and products.

CARD MRI's reach now extends beyond financial services. In 2012, it hosted a summit on the link between poverty and health, which resulted in an agreement to push for national reform. CARD's own business activities have contributed to a dramatic increase in the number of people covered by micro insurance services; by 2010 , about 21 percent of insured Filipinos received insurance through one of its MRIs. To achieve CARD MRI's ultimate goal of making financial services widely available and affordable for the rural poor, they had to engage with government at the very highest levels, acquiring the necessary operating licenses and driving the policy changes necessary for the microfinance sector to take root and grow.

\section{As Hybrid}

When working with nonprofits, Asian governments incline toward grantgiving. As noted, more than 50 percent of some SDOs' budgets come from government contracts. This dependency poses a concern for some founders and managers, whose revenues are vulnerable to changes in administration or government spending priorities.

As will also be discussed in Chapter 8, alternative models are on the rise. In Taiwan, Eden Welfare Foundation (EWF), whose revenues amounted to around US\$40 million in 2014, has shifted. Historically dependent on government funding and recognizing the need for a more sustainable income stream, the organization has recently focused on developing income from its social enterprise arm. It now contracts out trained disabled workers to provide cleaning, baking and other services to privatesector and government clients.

In Hong Kong, the Haven of Hope Christian Service $(\mathrm{HoH})$ also diversified. For years, $\mathrm{HoH}$ has received public funding to deliver essential health care services to the population under the Hospital Authority. With 
a staff of over 2000, this faith-based nonprofit provides integrated medical and social services at 46 locations, serving some 100,000 people since it was founded in the 1950s by missionaries. In 2012-2013 it received 51 percent of its US\$55 million budget from the Hong Kong government, with the rest from a combination of fundraising, donations, grants, and investment returns.

The challenge for the Haven of Hope is to strike a balance between serving the health care needs of the community while staying true to its founding mission and values. It has done so by directing its self-generated funds toward activities that align with its spiritual values that are not covered in its public remit. One such area is palliative care services, for which there is a dearth of facilities in Hong Kong, which lagged behind Taiwan, Singapore, Japan, and South Korea in the Quality of Death Index, the Economist Intelligence Unit's 2015 assessment of end-of-life care. Seeking to fill this gap, Haven of Hope established the Sister Annie Skau Holistic Care Center in 2006 to care for the mind, body, and spirit of the terminally ill, directing resources where the health care system was unable or unwilling. Today, the center runs itself on a social enterprise model, relying on donations for only 15 percent of its expenditure.

Hong Chi Association has also been a long-time beneficiary of Hong Kong government grants, which amounted to US\$70 million for the 2014-2015 financial year. It has embarked on a pilot project in which it hopes to forge a new sort of procurement relationship. Established in 1965 to provide educational services to the mentally handicapped, Hong Chi Association sends people with intellectual disabilities to collect used glass bottles and process them for the production of eco-bricks. In the first of its kind project funded by the charitable arm of the Hong Kong Jockey Club, Hong Chi Association is working closely with the Environmental Protection Department in the hope that by 2018 , it will be hired as a preferred vendor for the government's glass recycling scheme.

\section{For Policy Change}

As nearly all of our case studies indicate, government partnerships across the region follow a spirit of pragmatism. When it comes to social delivery, the organizations studied show signs that they are less inclined toward changing the status quo and more interested in solving a problem at hand; two-thirds focus entirely on creating a direct impact for their beneficiaries, with no agenda or inclination to participate in the policy discourse. For the 
vast majority of Asian SDOs, maximizing the number of people whose lives have been improved is the self-purported goal.

When they do seek policy change in the interests of their beneficiariesbe it to champion the rights of disabled people in Taiwan in the case of Eden Welfare Foundation, or to improve public benefits for the elderly in Japan as was the mission for Sawayaka Well-being Foundation-they tend to do so through a collaborative approach, as opposed to adversarial. This manifests itself in organizations that begin life in an advisory capacity. Founders are typically respected thinkers or practitioners with existing cache within the country, and often abroad. Whether they be from within the establishment or having worked with friendly international entities, they have come from a background where they have worked with or on behalf of government entities. They have created these new organizations not to challenge the status quo, but to provide expertise and the knowhow to help move it along.

\section{As National Expert}

The founder of Coral Triangle Center (CTC), an Indonesian organization at the forefront of domestic efforts to drive sustainable use of marine resources, is one case in point. Rili Djohani worked for the World Wildlife Fund in developing its marine conservation portfolio and joined the Indonesian branch of The Nature Conservancy to help establish its coastal and marine programs, including one in Bali. From 2004 to 2008 she was TNC's country director for Indonesia with responsibility for forest and coastal management.

However, international NGOs in Indonesia cannot raise money inside the country, which for Djohani limited their ability to be self-sufficient and truly responsive to domestic needs. With the support of prominent backers with a concern for the environment, the Coral Triangle Center headquartered in Bali was established. Indonesian businessman George Tahija and diplomat and government veteran Hasyim Djalal were founding directors, alongside Made Subadia, a top Indonesian conservation official.

Djohani's expertise and ability to represent domestic interests in international circles quickly raised CTC's profile as the national authority on issues of marine conservation. CTC is the only domestic partner involved in the Coral Triangle Initiative, a formal pact by the six nations that flank the beautiful Coral Triangle waters-waters highly vulnerable to ecosystem damage. The other seven conservation partners selected are from the 
major international agencies that Djohani used to work for and with. CTC is also well placed to communicate directly with the government on such matters of ocean governance, with two board members who represent the Indonesian government on maritime and external affairs.

For Arunabha Ghosh, getting the ear of policymakers was initially a tricky task, but one that he believed was critical in the face of India's looming environmental crisis. As a respected global thinker on climate governance, Ghosh had previously worked at the World Trade Organization, the United Nations Development Program, and as an author of the annual Human Development Report. He became increasingly concerned with the paucity of data and information available to Indian policymakers on issues of sustainable development. In 2010, this drove him to accept a challenge from business and policy leaders in India and build an independent research organization, the Council for Environment, Energy and Water (CEEW).

Going against the grain of India's traditionally noisy advocacy groups, CEEW seeks to affect policy change on the strength of its research and the evidence it generates. With the support of prominent Indian business leaders, and importantly, a board co-chairman in former Union-level minister for environment and forests, fertilizers and power, and heavy industry and public enterprises Suresh Prabhu, Ghosh and his research team aspired to provide the data that policymakers required to make well-informed decisions on important issues of resource management and environmental governance.

Although it was conceived first and foremost to fill a vacuum for reliable empirical data on policy issues, engaging with government has been one of the more difficult aspects of CEEW's mission. "It is hard to get access to government in Asia, and no one is going to compliment you or even acknowledge your work at times. It can be like selling yourself from scratch, every time," said Ghosh. But CEEW has continued to parlay its expertise in government circles and developed a much deeper engagement over the years.

The appointment of Prabhu as minister of railways under the new National Democratic Alliance government in 2014 has now also provided CEEW with a direct line into the Indian government at the highest levels. With its growing caché and largely on the strength and relevance of its original data and research, CEEW has been invited to advise government on more than 140 occasions, both in India and abroad. 
In politically volatile Thailand, the Foundation for Slum Child Care's (FSCC) was established in 1981 in part to fill what its founders viewed as a failure of the public welfare system. Public childcare for those under the age of two is not available in Thailand. The shortfalls of this were most evident in Bangkok's slums in the 1980s, where a generation of babies and young children was born into miserable conditions while lacking adequate care and supervision. FSCC came under the royal patronage of the late HRH Princess Galyani Vadhana and become a reputable provider of childcare services and professional training, caring for 2133 young children in 2014 .

Although its raison d'etre was to plug gaps in social service provision that the government was not inclined to fill, FSCC eventually would take a more strategic approach, like CARD-MRI, to circumvent what it saw as bad policy. The requirements for childcare providers to register with the Ministry of Social Development and Human Security were so onerous that the vast majority of centers were unable to meet them. This encouraged an unregulated grey sector for childcare, leaving large numbers of children vulnerable to mistreatment.

So FSCC brokered a deal with the government. Through its community networks, it would recruit unregistered community-level childcare centers, and provide proprietors with professional training under its Network for Childcare Services Co-development scheme. Those who passed the course received an FSCC certification, and with this they would be able to register formally with the ministry. FSCC's royal pedigree and professional reputation made it a trusted partner in the eyes of both government actors and informal operators. And it came with a good proposal, approaching the government with a solution that precluded the need for policy reform-a challenging task at a time when Thailand's political environment is so in flux. The government agreed. As of 2014, 81 childcare centers from 67 communities within Bangkok had been trained by the FSCC under this program.

\section{As BeLlwether}

More than in other East Asian nations, civil society in South Korea has been a consistent channel for questioning and challenging political repression.

Against this backdrop, World Without Worries for Shadow Education (WWW), a group seeking to effect change in South Korea's education policy, operates in a more confrontational fashion than either CTC or CEEW but with a comparable emphasis on research and data to inform their conversations with the government. Like protesting farmers, Song In-soo had 
no qualms about deploying attention-grabbing tactics as part of his organization's efforts to reform the education system. He saw that it was placing enormous pressure on Korean students desperate to beat their competitors for one of a handful of seats at its elite universities. This manifested in the form of a "shadow" industry of cram schools, which Korean parents were willing to invest in to ensure the success of their children, sometimes to the detriment of their mental health. In a worrying 2011 report, the National Teachers Labor Union reported that student suicidal impulses were primarily the result of too much time in cram schools and a fear of poor marks.

Former educator Song established the Citizens' Ministry of Education under WWW with a mission to address the worries of desperate parents who were concerned for the well-being of their children but also scared of them losing their edge in the fierce competition for university places. The Citizen's Ministry compiled data and conducted research to inform its case for the reform of pre-university education, finding that the bar for English language ability for the high school admissions test had been set too high. This gave those who were able to pay for additional tutoring or cram school preparation an unfair advantage. In 2009, the Ministry of Education lowered English language proficiency levels of the tests, causing some cram schools to close-household spending on shadow education dropped for the first time in 20 years.

The Citizen's Ministry ramped up its efforts in 2012, when WWW members staged one-person protests over 100 days in a public open space known as Gwanghwamun in central Seoul, wearing signs urging passersby to support education reform. Recognizing a shift in public sentiment around this issue, political leaders had even sought to promote these reforms in collaboration with WWW. But wary of appearing too close to the fray, WWW maintained its independence with its efforts contributing to the passage of a national law regulating shadow education activities within the public school system. Unlike CTC in Indonesia or CEEW in India, WWW did not seek to co-opt government to effect change, but instead focused its efforts on changing public perceptions and building an evidence-based case for reform that it could take to legislators.

\section{To SCALE}

Scale is a clear driver for such increased engagement. Many Asian governments have a governance infrastructure that runs right down to the township and village levels, where the local representative acts as the gateway to 
serving local communities. This is particularly true in the larger democratic nations of India, Indonesia, and the Philippines, where responsibility for public service provision tends to be more decentralized and devolved to officials at the sub-national levels. In fact, even when avoiding national government, many of the SDOs in our study developed relationships with the local government to ease the path to operating in new areas even if their initial instinct is to give wide berth to bureaucracy. Some organizations spoke of conceding agility when it comes to entering into arrangements with governments, who can either be a hindrance or help on the ground.

This was certainly the case for Magic Bus, an Indian youth development charity that began life as an informal club of adults teaching poor youngsters to play rugby. It grew into an organization that helps 300,000 children and teens through a network of 8000 mentors. When founder Matthew Spacie wanted to scale up their efforts nationally, he knew he had to approach the government in order to do so. "The first conversations we had with the government were very difficult, because we learned very quickly that you can't speak to the government unless you have some quantum of scale," he said of his initial outreach to the government. "We withdrew from conversations until we felt we had some firepower to have influence."

Magic Bus was awarded a UNICEF grant of US\$120,000 to expand coverage to 150,000 young people, up from the 4500 it was serving at the time. For the Indian government, the grant was a clear signal of Magic Bus's credibility as a potential partner. As Spacie and his team were devising their expansion plan in 2008, the central government launched its Village Youth Sport and Play Initiative. It was India's first initiative by the Ministry of Youth Affairs and Sports to promote social and physical development of rural youth, through which the government provided funds for the development and maintenance of sports grounds at the village level.

In 2010, the national government selected Magic Bus as a partner to implement centers for its new initiative in Maharashtra and Andhra Pradesh states. This was an opportunity for Magic Bus to establish itself to public officials as an effective partner for scaling up the ambitious scheme, instilling trust that it was a pair of safe hands for the job. To this end, when Magic Bus won the World Bank Development Marketplace Prize and received a US\$70,000 grant, Spacie spent the money on the measurement and evaluation of existing programs. This evidence of its impact imparted Magic Bus with the confidence it would need to earn the trust of government partners seeking the most effective organizations to work with. 
Some SDOs know from the start that they will need to engage with government at a certain point of development. Dr. Armida Fernandez made that choice quite deliberately for the Society for Nutrition, Education \& Health Action (SNEHA), which she had established in 1999. Her prior experience of working in a hospital in Mumbai's Dharavi slum showed her that it was not possible to drive significant change through delivery of health care services alone. Only arming Dharavi's residents with the knowledge to help themselves would prevent them from returning to hospital again and again, straining the public health system.

She set up SNEHA with the intention of changing attitudes among slum dwellers and literally bringing health care to the community. As of 2015 , it had made 4500 home visits to pregnant women and assisted more than 21,000 women with potential birth complications. It had also monitored the growth of nearly 24,000 children under three years of age in Dharavi, brought health care education to more than 10,000 children and adolescents, and intervened in more than 5000 incidents of violence against women and children. But Dr. Fernandez and her team thought it could achieve an even more lasting impact, by helping to build the capacity of the overstretched public health systems.

An opportunity to collaborate with government emerged from the City Initiative for Newborn Health (CINH), which was formed in partnership with the Municipal Corporation of Greater Mumbai, the public authority responsible for the Mumbai metropolis and suburban areas. CINH was tasked to reduce maternal and neonatal mortality in eight Mumbai wards and to assist some 283,000 people by developing systems for coordination between different levels of administration at the hospitals and clinics-a daunting task in a city of that scale.

Cognizant of how difficult it could be for NGOs to navigate India's bureaucracies and overcome inertia, the SNEHA leaders saw their role within this initiative as that of facilitator and moderator, helping to create an environment that was conducive to cooperation between the various stakeholders. At the first meeting of all those involved, Dr. Fernandez surprised many in the room by opening with praise of government health officials for their accomplishments. She acknowledged the difficulties government workers faced in their jobs, the constraints they faced, and their desire to make a positive difference to the communities they served.

This appreciative opening set the scene for CINH's approach, and it became the country's largest urban health initiative for maternal and newborn health. SNEHA worked with government counterparts to implement 
standardized clinical protocols and benchmarks at every tier of Mumbai's public health care system. Lines of communication were established between government hospitals, and standards were set for the transfer and tracking of patient cases between and within institutions. Data collection and analysis provided the government actors with rationales for action. When SNEHA examined government data to design the CINH program, it found mismatches between capacity and patient flows, leading to a reexamination of staffing capacity across facilities.

By creating a congenial environment that fostered collaboration between government and non-government actors, SNEHA helped overcome some of the friction associated with bureaucracy. Today, most of SNEHA's programs involve some level of contact with local government agencies, either through delivery of services or in its advocacy efforts. As of 2015 , it has trained more than 3000 public health care providers and 2900 government outreach workers.

\section{Conclusion: Strategies for Government Engagement}

Successful SDOs collaborate with governments in a variety of ways across Asia. In China, BNVS saw that the endorsement by CYDF gave it legitimacy, making donors feel safe in following the support of Beijing. In Malaysia, SRAM's objectives aligned so perfectly with those of the government that they came together in a marriage of convenience, where SRAM did the work of cultivating sporting talent from the ground up while the government channeled resources from top down. In India, CEEW shared its data with officials, improving their ability to make well-informed decisions.

Each of the social enterprises studied found government as a lucrative client, helping these firms to extend their reach and impact. This was particularly true for environmental-minded enterprises Landwasher and Tree Planet, which have benefited from government not only as consumers of their offerings, but also indirectly as recipients of resources officially channeled to growing the green economy in China and South Asia.

For those nonprofits reliant on government grants, strained public finances have prompted new models of funding. Some have established income-producing social enterprise arms. Eden Welfare Foundation in Taiwan and Hong Chi in Hong Kong now provide training and jobs for the disadvantaged with the view toward improving self-sufficiency of beneficiaries and the organizations themselves. This shift is consistent with the Wang Dao philosophy of philanthropy espoused by Taiwanese industrialist 
Stan Shih, who writes of the societal benefits reaped from doing well by doing good.

Only a handful of the SDOs studied had overt aspirations to change the policy environment for their chosen field, and even so, they chose to work with government cooperatively to fill gaps in technical expertise. With accumulated expertise from many years working in established international conservation groups, CTC's Djohani can assist with Indonesia's domestic priorities and provide direct advice to the government on how to better manage their ocean resources. Ghosh initially collaborated to gain access to policymakers, who now recognize the value of CEEW's independent, robust research in informing environmental policymaking. WWW's less-accommodating stance to partnering with government was specific to South Korea's noisy tradition of civil society process, but it still served as a useful bellwether for legislators to understand the shifting national mindset on education reform.

And as frustrating as it can be to engage with government bureaucracy, maturing SDOs recognize this as the only pathway to ramping up the impact of their efforts. Magic Bus gained the trust of government and has been able to expand its reach to 22 of India's 29 states through the national rural sports program. SNEHA realized that strengthening of the public health care system was the only way to drive better outcomes at scale, and to do this Dr. Fernandez fostered collaborative relationships between stakeholders. Inspired by the growth of the microfinance industry in Bangladesh, CARD hoped to establish the same in the Philippines by working with various stakeholders to create the policy environment, institutions, and products required. And in an environment where policy reform is a distant prospect, FSCC leveraged its royal seal of approval and grassroots appeal to broker a workaround that helped informal childcare providers to register with the Thai government, despite its onerous regulations.

Reasons for collaboration vary, as do the models employed and the degree of engagement in each case. But a partnership with government has been forged by nearly all of the 30 SDOs selected for this study. Across the board, these SDOs have deployed common strategies that have helped them to leverage their engagement with government relations to maximum effect.

For certain SDOs, government partnerships present few conflicts. The alignment of objectives between SRAM and the Malaysian government meant that their successes were mutual, making for an easy partnership. But this is a rarity in the social delivery sector, where agendas are often 
complex and less than perfectly matched. The SDOs most successful in cutting through the red tape were those that embraced it. Knowing that government officials tended to be overworked and beleaguered, SNEHA created an appreciative atmosphere to encourage collaboration between all actors to strengthen the health system.

But partnering with government does not mean co-option. In fact, an independent streak not only helps successful SDOs to avoid mission creep, but also allows them to appear as credible and valuable partners in the eyes of government. Despite the allure of research grants earmarked for specific policy questions, CEEW's prerogative to set its own research agenda is fiercely guarded by Ghosh. In this way, CEEW is able to remain clearminded on what it sees to be priorities of the day and to play its role casting the spotlight on them.

Mindful of the vagaries of government spending priorities, SDOs such as Eden Welfare Foundation are generating new revenue streams in efforts to become more self-reliant. But even organizations heavily dependent on government grants to deliver services have carved out the space to pursue their own interests. Recognizing a dearth of government resources flowing to palliative care in Hong Kong, $\mathrm{HoH}$ used alternative funds to set up an affordable hospice center. Such initiatives demonstrate the importance of maintaining the independence to identify gaps in public sector provision, and innovating to generate new solutions.

While CARD was ultimately dependent on government to facilitate the conditions for microfinance, it was very much the case of an SDO leading the government. Alip took the initiative in conducting research, generating funds, and planting the seeds for his grand vision to provide microfinance services to the rural poor.

Arguably the greatest successes achieved were those in which the SDO showed governments a better model for service delivery. Of the 30 SDOs studied, SWF's community model for elderly care, Magic Bus's mentorship system, New Homeland Foundation's approach to rebuilding disaster-struck communities, and CARD's delivery of microfinance services through the "aunties" of the countryside have all been adapted by government as national models for service delivery.

Such success speaks to the importance of the lesson: SDOs in Asia must work with authorities at some level. The nature and timing of collaboration varies with the country, the mission, and the organization, but the eventual relationship remains fundamental. For some SDOs, government partnerships are necessary even to begin operations, and for many more, they offer greater reach in their ongoing efforts. 


\section{Note}

1. In China, similar to several other Asian countries, there are GONGOs, which is an acronym for government operated non-governmental organizations. Seemingly oxymoronic in a Western context, it makes complete sense in Asia.

Open Access This chapter is licensed under the terms of the Creative Commons Attribution 4.0 International License (http://creativecommons.org/licenses/ by $/ 4.0 /)$, which permits use, sharing, adaptation, distribution, and reproduction in any medium or format, as long as you give appropriate credit to the original author(s) and the source, provide a link to the Creative Commons license and indicate if changes were made.

The images or other third party material in this chapter are included in the chapter's Creative Commons license, unless indicated otherwise in a credit line to the material. If material is not included in the chapter's Creative Commons license and your intended use is not permitted by statutory regulation or exceeds the permitted use, you will need to obtain permission directly from the copyright holder.

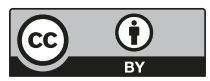

